\title{
Rapid Morphological Changes Caused by Intensive Coastal Development in Longkou Bay, China
}

\author{
Dong $\mathrm{Li}^{\dagger}$, Cheng Tang ${ }^{\ddagger}$, Xiyong $\mathrm{Hou}^{\ddagger *}$, and Hua Zhang \\ ${ }^{\dagger}$ Institute of Oceanology \\ Chinese Academy of Sciences \\ Qingdao, Shandong 266071, P.R. China \\ ${ }^{\sharp}$ Key Laboratory of Coastal Environmental \\ Processes and Ecological Remediation \\ Yantai Institute of Coastal Zone Research \\ Chinese Academy of Sciences \\ Yantai, Shandong 264003, P.R. China
}

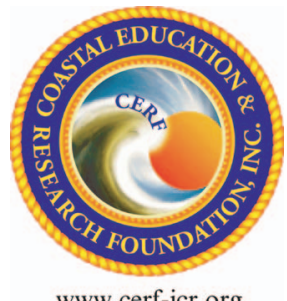

www.cerf-jcr.org

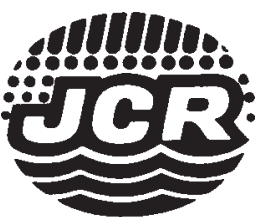

www.JCRonline.org

\section{ABSTRACT}

Li, D.; Tang, C.; Hou, X., and Zhang, H., 2019. Rapid morphological changes caused by intensive coastal development in Longkou Bay, China. Journal of Coastal Research, 35(3), 615-624. Coconut Creek (Florida), ISSN 0749-0208.

Analyses of the evolution of subaqueous topography in coastal water provide an understanding of the effects of intensive coastal development on bays and estuaries. Analysis of a series of historical bathymetric acoustic surveys has revealed large changes in morphology from the 1960s to 2010s in Longkou Bay, China. Water depths were extracted from digitized admiralty charts to explore the accretion-erosion characteristics in a geographical information system environment, providing quantitative estimates of morphological changes. Multibeam echosounders were used to map and analyze the geomorphologic features caused by the construction of artificial islands. Results illustrated that the shoreline and bathymetry of Longkou Bay have changed rapidly in recent decades. The subaqueous area decreased by about $15 \%$, while land area increased by more than $13 \mathrm{~km}^{2}$ in the study area during the last 50 years. From the $1960 \mathrm{~s}$ to $1990 \mathrm{~s}$, the evolution of Longkou Bay was mainly governed by natural processes with a patchy distribution of deposition and erosion, and there were few signs of change related to large-scale human activities. During the period from the 1990s to 2010s, intensive coastal developments, including large port engineering projects, channel dredging, and construction of artificial islands, became the main processes affecting morphological changes in Longkou Bay. The high-resolution bathymetric results near the artificial island showed that the seafloor was dredged at many sites, leaving large areas of borrow pits. The sudden change of the underwater topography will lead to the destruction of local benthic habitat, and effective measures need to be taken to protect and remediate the heavily disturbed subaqueous environment.

ADDITIONAL INDEX WORDS: Bathymetric charts, multibeam mapping, underwater morphology, artificial island, land reclamation.

\section{INTRODUCTION}

Morphological changes can have important implications for coastal environments, especially in a bay that has high commercial, recreational, and ecological value. Understanding the long-term morphological change in a bay can provide insights into the historical characteristics of the bay and help researchers to assess the impacts of natural changes and human activities on the coastal system. The likely long-term impacts of physical factors dominating the morphological changes generally include sea-level rise, sediment discharge, tide currents, and wave fields (Blott et al., 2006; Restrepo et al., 2016; Van der Wal, Pye, and Neal, 2002; Wang et al., 2013). Intensive coastal development such as channel dredging, harbor enlargements, sand excavation, and land reclamation can also influence the morphological changes (Van der Wal, Pye, and Neal, 2002; Zhang et al., 2015). During the last century or so, such human activities often have had a greater effect on the morphological development than natural forcing factors (Hou et al., 2016; Wang et al., 2013; Wu, Hou, and Xu, 2014), and few estuaries worldwide still preserve the original broad intertidal area (Wolanski, 2006). Knowledge of the

DOI: 10.2112 /JCOASTRES-D-18-00095.1 received 7 July 2018; accepted in revision 26 September 2018; corrected proofs received 5 November 2018; published pre-print online 3 January 2019.

*Corresponding author: xyhou@yic.ac.cn

${ }^{\circledR}$ Coastal Education and Research Foundation, Inc. 2019 natural and anthropogenic changes to coastal ecosystems and the design of successful restoration projects require knowledge of patterns of deposition and erosion.

Morphological processes in estuaries have long been investigated by scientists and coastal engineers (Fenster and FitzGerald, 1996; Harris and Collins, 1984; Van der Wal, Pye, and Neal, 2002; Wang, Li, and Li, 2013). Process-based models are regularly used to study morphological changes quantitatively. Short-term changes can often be satisfactorily predicted using hydrodynamic and morphodynamic models (Townend, 2005). Long-term geomorphologic evolution can be simulated using statistical models (Blott et al., 2006; Wang et $a l .$, 2013). However, geological and geomorphological evolution models have inherent limitations due to the lack of detailed physics (Blott et al., 2006; Zhang et al., 2015). Geographical information system (GIS) integration and field measurements are effective ways to quantify the long-term morphological changes, and it is possible to elucidate accretion-erosion characteristics from a large-scale perspective by analyzing a long sequence of bathymetric surveys.

For most coastal areas, bathymetric charts and surveys can offer historical information on coastal morphology. Navigational charts, which provide bathymetric information over a vast period of time, are a valuable data source for studying patterns of morphological change. Admiralty charts can be digitized in a GIS, and the data can then be recorded, stored, and analyzed to build an underwater digital elevation model 


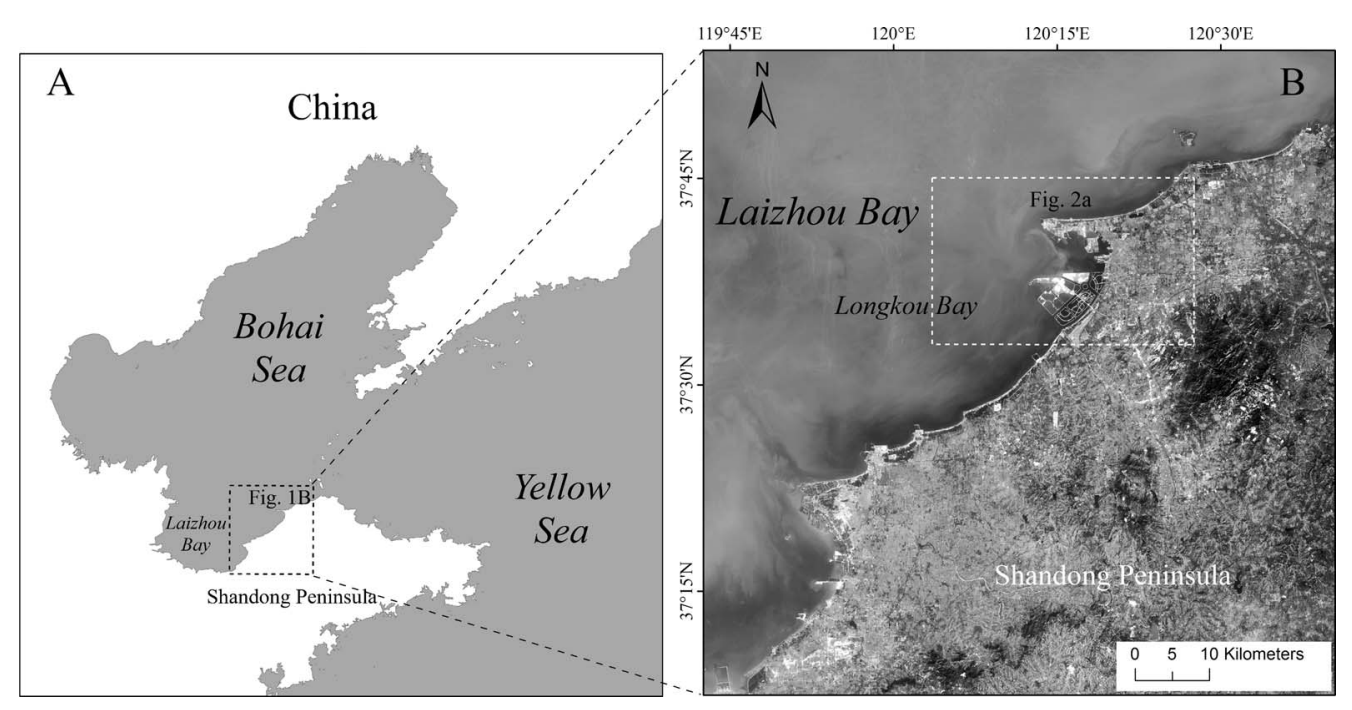

Figure 1. Location of the study area in the southern Bohai Sea, China.

(DEM) for further spatial analysis, to calculate sedimentation and erosion rates, for example (Van der Wal and Pye, 2003).

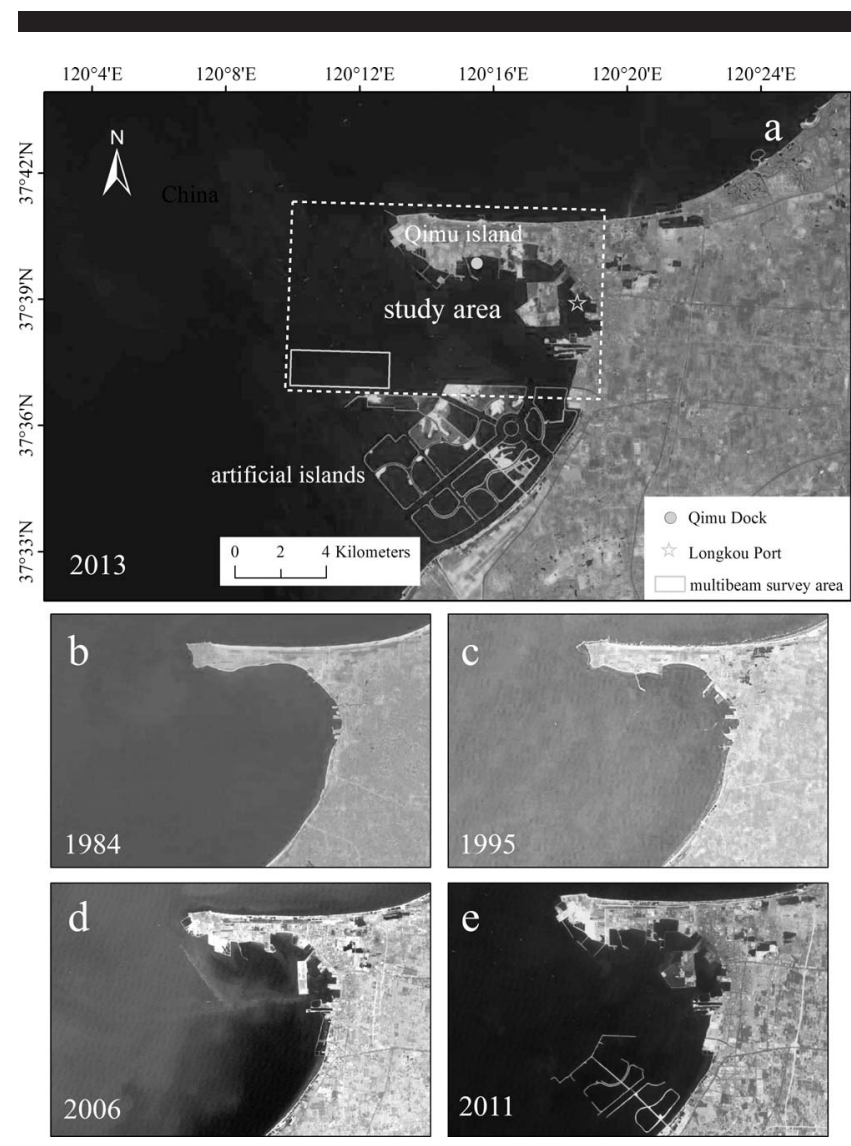

Figure 2. (a) Location of the study area in Laizhou Bay. (b)-(e) Comparison of the morphological changes of Longkou Bay from multitemporal LandSat images.
This technique has been successfully applied in a wide variety of estuarine areas, including the Ribble Estuary (Van der Wal, Pye, and Neal, 2002), the Mersey Estuary (Blott et al., 2006), the Yangtze Estuary (Wang et al., 2013), the Pearl River Delta (Zhang et al., 2015), and Lingding Bay (Wu et al., 2016). Understanding of the morphological evolution and related changes in a bay system is necessarily based on reasonably good knowledge of the leading triggering processes (JabaloySánchez et al., 2010). There is no doubt that the evolution of bay morphology is closely associated with socioeconomic development. In many parts of the world, reclaiming land from the sea has now become a common practice (Radhi, Sharples, and Assem, 2015). Longkou Bay in China (Figure 1) has also been affected by human activities, and morphological changes are clearly shown on multitemporal remote-sensing images (Figure 2).

Although admiralty charts can be used to demonstrate a comprehensive overview of morphological changes quantitatively, they cannot provide detailed geomorphologic characteristics due to their inadequate accuracy. The development of acoustic seafloor mapping methods has allowed for the creation of detailed seabed morphology maps, and recent developments in multibeam bathymetric survey technology have enabled the visualization of submarine landforms in three dimensions (Kan et al., 2015). High-resolution swath mapping using multibeam echosounding (MBES) allows large areas of the seafloor to be mapped with great detail. Therefore, the objectives of this study were to quantitatively elucidate the rapid morphological changes using the admiralty charts for Longkou Bay in recent decades and show the geomorphologic features caused by the construction of artificial islands using multibeam swath mapping.

\section{Study Area}

Longkou Bay extends from $37^{\circ} 33^{\prime} \mathrm{N}$ to $37^{\circ} 42^{\prime} \mathrm{N}$ and from $120^{\circ} 09^{\prime} \mathrm{E}$ to $120^{\circ} 20^{\prime} \mathrm{E}$ in the southern Bohai Sea, north of the Shandong Peninsula, China (Figures 1 and 2). It is a semi-open 
bay with a mouth of $13.4 \mathrm{~km}$. As a part of Laizhou Bay, the region is controlled by a temperate continental monsoon climate, and the direction of the dominant waves is NE (Wang $\mathrm{Li}$, and $\mathrm{Li}, 2016$ ). The tidal regime in the study area is mixed semidiurnal. The coastal area is characterized by shallow plains, and the coastline is composed of bedrock and sand. Sediments in Longkou Bay are mainly silty clays, and the grain size of the sediments gradually decreases from inside of the bay to outside (An et al., 2010). The water depth is less than $10 \mathrm{~m}$ in most of the bay. As a diversion dike, Qimu Tombolo can increase the flow velocity to form a deep trough, and the deepest site at $23 \mathrm{~m}$ is located northwest of Qimu Island. Based on data availability, a part of Longkou Bay was chosen as the study area (Figure 2a) to reveal the morphological changes in recent decades.

The Longkou Port has been the largest domestic port trading with Africa in China since 2009, with throughput of over 70 million tons in 2014, and it will grow up to 100 million tons by 2020. Today, the main channel is $15.5 \mathrm{~m}$ in depth and $200 \mathrm{~m}$ in width, allowing access for ships up to the 100,000 ton level. Early in the 1980s, small-scale coastal land reclamation took place in Longkou Bay. In recent decades, with the enlargement of Longkou Port and the continued improvement of infrastructure around the port, large volumes of coastal waters have been occupied, and the sea area near the port has been deepened by dredging. Moreover, with the development of technology and growth of the population, the local government began largescale artificial island construction to support private sector development, particularly in the ecotourism and the high-tech industries. As China's largest artificial islands (Figure 2a), the Longkou artificial islands, covering $45 \mathrm{~km}^{2}$, were built in the sea at a distance from the coast to protect the natural coastline and reduce the loss of marine ecology. A huge reclamation project began in January 2011, and a $120 \mathrm{~km}$ cofferdam was completed in the first half of 2012. The large-scale artificial island projects greatly changed the morphology of Longkou Bay, including the land and underwater areas.

\section{METHODS}

The historical time series of admiralty charts were analyzed in a GIS environment, and detailed geomorphologic characteristics of the seafloor near the artificial island were obtained using a MBES. The estimates of underwater topography changes and current features were quantitatively demonstrated through the analysis of DEMs from the digitized admiralty charts and multibeam swath mapping.

\section{Admiralty Chart Processing}

Bathymetric surveys in Longkou Bay have been carried out many times throughout the latest decades. To quantitatively estimate the morphological changes in Longkou Bay, five historical time series of admiralty charts were collected in this region, and the detailed information is shown in Table 1 . The admiralty charts for each period were a composition of surveys and do not represent the bathymetry at a single point in time. Although water depth measurements may have some inherent errors, such as correction of tidal level, boat posture, and wave effects, etc., they are generally not considered to be large enough to cause serious calculation errors due to the maturity
Table 1. Admiralty charts used in the study.

\begin{tabular}{lcccc}
\hline \hline Publisher & Chart No. & Publish Date & Survey Date & Scale \\
\hline NGD & 10302 & $1966 / 04$ & $1963 / 1964$ & $1: 15,000$ \\
NGD & 11892 & $1984 / 05$ & $1980 / 1982$ & $1: 15,000$ \\
NGD & 11892 & $1999 / 08$ & $1994 / 1996$ & $1: 15,000$ \\
NGD & 11892 & $2011 / 08$ & $2007 / 2009$ & $1: 15,000$ \\
MSA & 34112 & $2014 / 02$ & $2012 / 2013$ & $1: 25,000$ \\
\hline
\end{tabular}

NGD = the Navigation Guarantee Department of the Chinese Navy Headquarters, MSA = Maritime Safety Administration of the People's Republic of China

of the technology (Wang et al., 2013). A significant source of inaccuracy in the measured elevations recorded in bathymetry charts arises from inconsistencies in the datum levels in relation to tides (Van der Wal and Pye, 2003). To account for this, the water depths used in this study were referenced to the lowest astronomical tide (LAT).

Using the latitude/longitude information, each admiralty chart was georeferenced into the UTM WGS84 coordinates of China. Then, the isobaths, spot depths, and bay outlines were digitized to the same datum in a GIS (i.e. ArcGIS software). The kriging approach, which can provide a good interpolation for sparse data when sufficient data points are available to compute variograms (Burrough, 1987), was used to interpolate the depth points, for building an underwater DEM with $50 \times 50$ $\mathrm{m}$ resolution. Using the spatial analyst tools, the DEMs for multiple periods were compared to calculate volumetric changes in order to quantitatively estimate the morphological changes, such as isobath evolution, scour, and silting development in this area. A conservative approach was applied in this study, the same as previous studies, which suggested that elevation changes greater than $\pm 0.5 \mathrm{~m}$ between subsequent surveys can be considered significant (Blott et al., 2006; Van der Wal, Pye, and Neal, 2002; Zhang et al., 2015). Although the estimated quantities for sediment volume, in particular, are unlikely to be truly accurate, the data are considered to provide a reliable indication of relative net accretion and erosion trends during different time periods (Blott et al., 2006). All height and depth values extracted from charts were converted into meters to allow volumes to be calculated.

\section{Multibeam Swath Mapping}

In order to obtain the detailed depth information in this area, and to further understand the underwater topography changes caused by the construction of artificial islands, a rectangular area spanning $4.4 \times 1.6 \mathrm{~km}^{2}$ near the artificial island (Figure 2) was selected for multibeam swath mapping. The survey was performed from 27 May to 2 June 2016 using an MBES (Sonic 2024, R2 Sonic, LLC) pole mounted on the research vessel. The system produced 256 beams, operated at a frequency of 400 $\mathrm{kHz}$, and gave a swath width at $130^{\circ}$ of more than 4 times water depth. The navigation system used was the differential global positioning system (DGPS; Hemisphere, Inc., Canada), with an Octans IV gyrocompass and motion sensor (iXBlue, France), which provided submeter and $0.01^{\circ}$ accuracy for heave, roll, and pitch. Real-time sound speed was measured using a sound velocity sensor (Minos SVP, AML ${ }^{\mathrm{TM}}$, Canada) that was installed near the transducers for beam steering. Offsets between sensors were measured from the survey ship. Angular misalignment among transducer, gyrocompass, and motion 


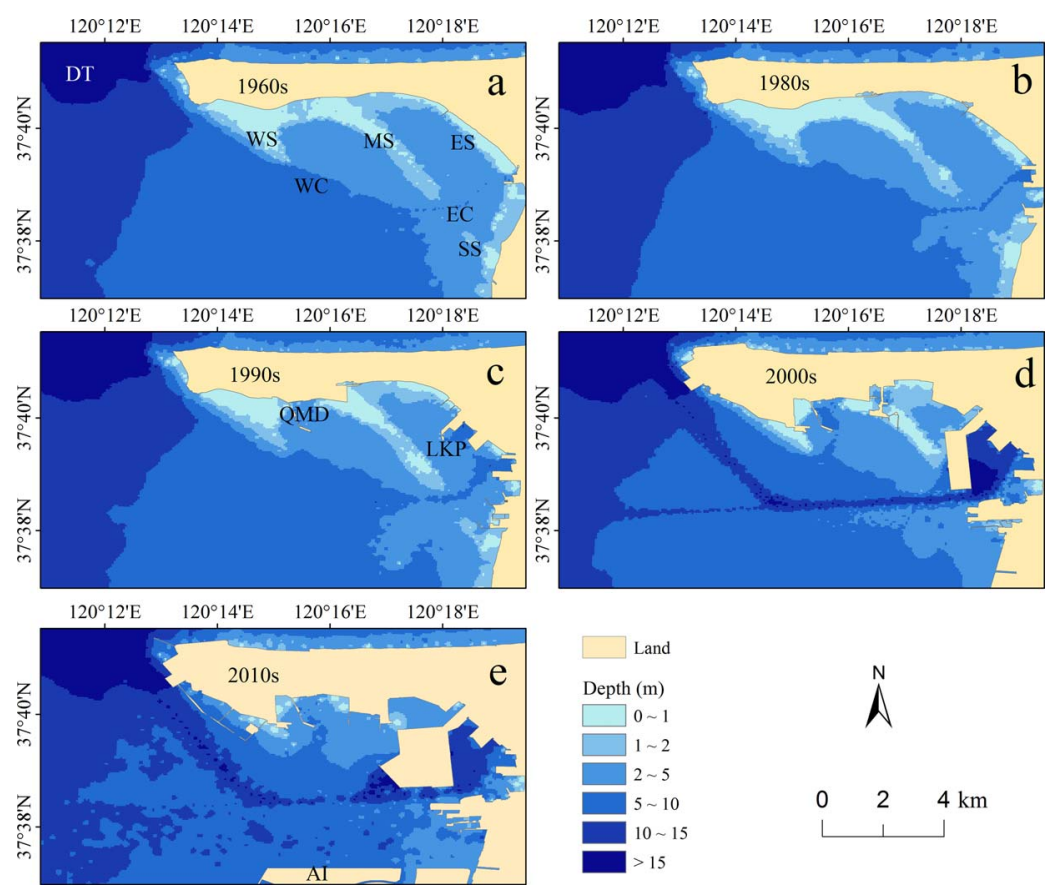

Figure 3. Digitized bathymetry charts of Longkou Bay from 1960s to 2010s: (a) 1960s, (b) 1980s, (c) 1990s, (d) 2000s, (e) 2010s. The abbreviations marked in the figure are indicated: west shoal (WS), middle shoal (MS), east shoal (ES), south shoal (SS), west channel (WC), east channel (EC), deep trough (DT), Qimu Dock (QMD), Longkou Port (LKP), and artificial islands (AI).

sensor was calibrated by a patch test before the survey. Data logging, real-time quality control, display, and navigation were conducted using QINSy v8.1 (QPS, The Netherlands). Sound velocity profiles were also taken during data acquisition every 3 hours at different depths to account for variations in sound speed in the water column. The vessel's speed was maintained at around 6 knots, and the distance between each parallel survey line was $30 \mathrm{~m}$ to assure $100 \%$ coverage of the area.

Raw multibeam data were processed using Caris HIPS/SIPS 8.1 (Caris, Canada). Postprocessing steps included editing, cleaning, and calculating the calibration parameters (i.e. roll, pitch, and heading). The combined uncertainty and bathymetry estimator (CUBE) surface was used as a cleaning tool and for product gridded surface creation. Soundings were weighted and contributed to surface grid nodes based on total propagated uncertainty (TPU) values during the CUBE surface creation. Tidal correction was applied to depth soundings using verified tide data derived from Longkou tide station. Finally, processed bathymetry data were gridded at $0.5 \mathrm{~m}$ spatial resolution and imported into ArcGIS v.10.2 for further processing and evaluation.

\section{RESULTS}

Figure 3 shows the bathymetric charts in Longkou Bay that were used to estimate the subaqueous morphological changes in this area. The analyses of the bathymetric changes are shown in Figure 4. The land and subaqueous area in the study area have changed significantly in recent decades. The subaqueous area decreased by about 15\%, while land area increased by more than $13 \mathrm{~km}^{2}$ from the $1960 \mathrm{~s}$ to $2010 \mathrm{~s}$ (Tables 1 and 2). The change was not gradual but occurred abruptly from the $1990 \mathrm{~s}$ to $2010 \mathrm{~s}$. The morphological changes in the Longkou Bay study area can be divided into three stages, 1960s-1990s, 1990s-2000s, and 2000s-2010s.

\section{0s-1990s}

The subaqueous topography of Longkou Bay (Figure 3a,b,c) essentially maintains a configuration with one deep trough, four shoals (west shoal, middle shoal, east shoal, south shoal), and one channel, composed of the west channel and east channel. In general, prior to the 1990 s, there had been no major morphological changes for a 30 year period, and the system was largely in equilibrium. From the 1960 s to 1980 s, more than $3 / 4$ of the sea area showed no significant depth change (Table 3), with about $1 / 5$ of the area showing erosion (Figure $4 \mathrm{a}$ ). The average water depth in the study area increased from $7.19 \mathrm{~m}$ to $7.43 \mathrm{~m}$, and the subaqueous area shrank from $85.12 \%$ of the study area in the 1960 s to $84.99 \%$ in the 1980 s (Table 2). Figure 4a shows that the depth of the deep trough, Longkou Port, and east channel decreased slightly more than $0.5 \mathrm{~m}$, and the morphology of the west shoal, middle shoal, and south shoal changed as a result of minor deposition of less than $1 \mathrm{~m}$. From the 1980 s to 1990 s, more than $80 \%$ of the subaqueous area had significant depth change, with the deposition and erosion area accounting for about 10\%, respectively (Figure $4 \mathrm{~b}$; Table 3 ). During this period, the deep trough continued to deepen, but deposition occurred in some local areas (Figure 4b). The depth of the middle shoal and south shoal continued to increase, and relatively minor deposition occurred, while erosion of less than 

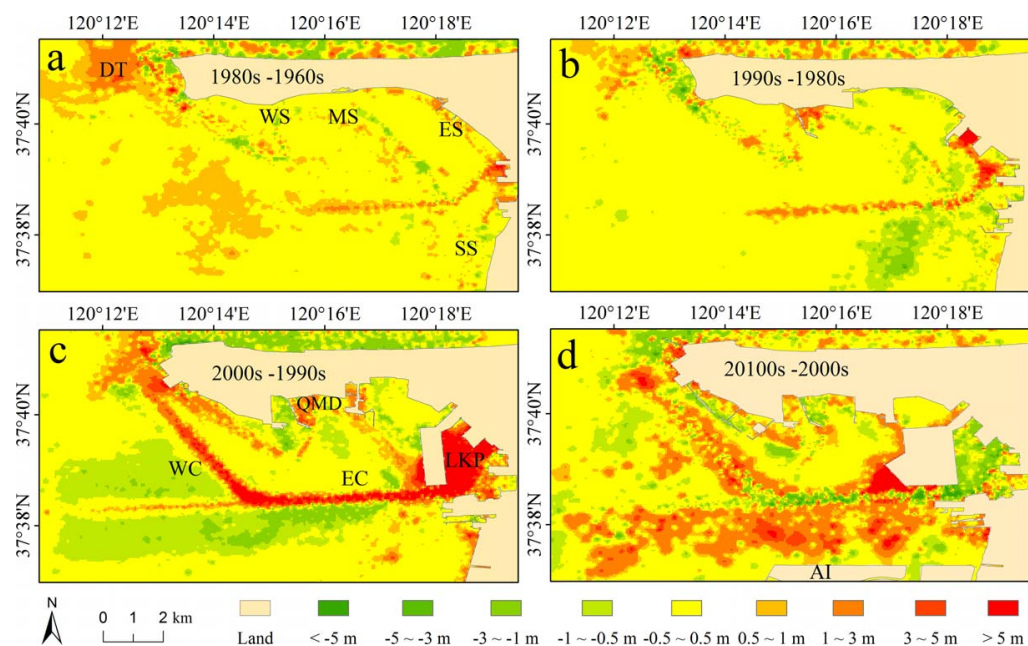

Figure 4. Bathymetric changes (depth of later time minus that of the previous time) in Longkou Bay in the following periods: (a) 1960s-1980s, (b) 1980s-1990s, (c) $1990 \mathrm{~s}-2000 \mathrm{~s}$, (d) 2000s-2010s. The abbreviations marked in the figure are the same as Figure 2.

$1 \mathrm{~m}$ could be detected in the west shoal. With the enlargements of Longkou Port, the area of the east shoal gradually decreased from the 1980 s to $1990 \mathrm{~s}$, and notable dredging to depths of over $3 \mathrm{~m}$ took place near the port. Compared with the $1980 \mathrm{~s}$, the Qimu Dock was expanded, and the channel dredging intensity increased in the $1990 \mathrm{~s}$. Thus, the depth exceeding $1 \mathrm{~m}$ decreased near Qimu Dock, and there was a remarkable depth change of $1-3 \mathrm{~m}$ in east channel (Figure $4 \mathrm{~b}$ ).

\section{0s-2000s}

During the 1990s-2000s, evidence of human activities increased markedly. Most of the east and south shoals disappeared. The west shoal aggraded less than $1 \mathrm{~m}$, while minor erosion of less than $1 \mathrm{~m}$ occurred in the middle shoal. Similarly, the area of the middle shoal and west shoal gradually decreased as a result of coastal land reclamation of Qimu Island. The proportion of subaqueous area (Figure 3c,d) decreased from $82.9 \%$ of the study area in the 1990 s to $78.2 \%$ in the 2000s (Table 2). The mean water depth of the study area increased from $7.56 \mathrm{~m}$ in the $1990 \mathrm{~s}$ to $8.16 \mathrm{~m}$ in the $2000 \mathrm{~s}$. From the $1990 \mathrm{~s}$ to $2000 \mathrm{~s}$, the area of erosion grew to $18.85 \%$, and the

Table 2. Land and subaqueous areas in the Longkou Bay study area, 1960s-2010s.

\begin{tabular}{lrrrrr}
\hline \hline & \multicolumn{5}{c}{ Year } \\
\cline { 2 - 6 } & $1960 \mathrm{~s}$ & $1980 \mathrm{~s}$ & $1990 \mathrm{~s}$ & $2000 \mathrm{~s}$ & $2010 \mathrm{~s}$ \\
\hline Land area $\left(\mathrm{km}^{2}\right)$ & 15.78 & 15.92 & 18.15 & 23.10 & 29.35 \\
Subaqueous area $\left(\mathrm{km}^{2}\right)$ & & & & & \\
$0-1 \mathrm{~m}$ & 4.48 & 4.17 & 3.38 & 1.93 & 0.40 \\
$1-2 \mathrm{~m}$ & 5.54 & 5.06 & 4.81 & 3.10 & 1.56 \\
$2-5 \mathrm{~m}$ & 20.47 & 19.80 & 19.67 & 16.26 & 13.50 \\
$5-10 \mathrm{~m}$ & 37.11 & 36.46 & 36.09 & 36.49 & 31.52 \\
$10-15 \mathrm{~m}$ & 18.08 & 19.26 & 18.61 & 18.30 & 23.37 \\
$>15 \mathrm{~m}$ & 4.62 & 5.44 & 5.42 & 6.78 & 6.44 \\
Subtotal & 90.29 & 90.19 & 87.98 & 82.85 & 76.78 \\
Subaqueous area $(\%)$ & 85.12 & 84.99 & 82.90 & 78.20 & 72.34 \\
Mean water depth $(\mathrm{m})$ & 7.19 & 7.43 & 7.56 & 8.16 & 8.89 \\
Water volume $\left(10^{6} \mathrm{~m}^{3}\right)$ & 649.15 & 670.11 & 665.09 & 676.06 & 682.57 \\
\hline
\end{tabular}

area of deposition increased to $28.70 \%$ of the subaqueous area (Table 3). The area of the deep trough expanded to the island and continued to deepen to a small extent (Figures $3 \mathrm{~d}$ and $4 \mathrm{c}$ ). Compared with the 1990 s, the most significant changes in the 2000s were that Longkou Port expanded over a large area, and the channel widened and deepened correspondingly (Figure $3 c, d)$. The deep-water area was enlarged near Longkou Port, and the depth on the east side of the wharf was more than $20 \mathrm{~m}$. The depth of the navigation channel (including west channel and east channel) was deepened to more than $10 \mathrm{~m}$, locally reaching over $15 \mathrm{~m}$ (Figure $3 \mathrm{~d}$ ). Figure 4c displays a notable polygonal line with depth changes larger than $3 \mathrm{~m}$ or $5 \mathrm{~m}$ along the navigation channel. Areas of aggradation were created near the channel by dumping of excavated sands. In addition,

Table 3. Sizes and changes of deposition and erosion areas, water column, and land area in the Longkou Bay study area during 1960s-2010s.

\begin{tabular}{|c|c|c|c|c|}
\hline & \multicolumn{4}{|c|}{ Time Period } \\
\hline & $\begin{array}{c}1960 \mathrm{~s}- \\
1980 \mathrm{~s}\end{array}$ & $\begin{array}{l}1980 \mathrm{~s}- \\
1990 \mathrm{~s}\end{array}$ & $\begin{array}{l}1990 s- \\
2000 s\end{array}$ & $\begin{array}{l}2000 s- \\
2010 s\end{array}$ \\
\hline \multicolumn{5}{|l|}{ Deposition area $\left(\mathrm{km}^{2}\right)$} \\
\hline$<-5 \mathrm{~m}$ & 0.00 & 0.04 & 0.04 & 0.18 \\
\hline-5 to $-3 \mathrm{~m}$ & 0.13 & 0.09 & 0.17 & 0.55 \\
\hline-3 to $-1 \mathrm{~m}$ & 2.25 & 2.45 & 5.96 & 4.17 \\
\hline-1 to $-0.5 \mathrm{~m}$ & 2.22 & 6.59 & 17.65 & 7.28 \\
\hline \multicolumn{5}{|c|}{ No significant change area $\left(\mathrm{km}^{2}\right)$} \\
\hline-0.5 to $0.5 \mathrm{~m}$ & 68.58 & 70.66 & 43.53 & 37.95 \\
\hline \multicolumn{5}{|l|}{ Erosion area $\left(\mathrm{km}^{2}\right)$} \\
\hline $0.5-1 \mathrm{~m}$ & 12.76 & 4.35 & 5.03 & 8.71 \\
\hline $1-3 \mathrm{~m}$ & 4.08 & 3.27 & 5.32 & 14.76 \\
\hline $3-5 \mathrm{~m}$ & 0.26 & 0.43 & 2.02 & 2.42 \\
\hline$>5 \mathrm{~m}$ & 0.05 & 0.25 & 3.28 & 0.91 \\
\hline $\begin{array}{l}\text { Percentage of } \\
\text { deposition area }(\%)\end{array}$ & 5.09 & 10.40 & 28.70 & 15.83 \\
\hline $\begin{array}{l}\text { Percentage of } \\
\text { erosion area }(\%)\end{array}$ & 18.98 & 9.42 & 18.85 & 34.83 \\
\hline $\begin{array}{l}\text { Water volume } \\
\text { net gain }\left(10^{6} \mathrm{~m}^{3}\right)\end{array}$ & 20.96 & -5.02 & 10.97 & 6.51 \\
\hline Land area gain $\left(\mathrm{km}^{2}\right)$ & 0.14 & 2.23 & 4.95 & 6.25 \\
\hline
\end{tabular}


the Qimu Dock maintained its state of expansion as in the period of the $1980 \mathrm{~s}-1990 \mathrm{~s}$, and the sea area near the dock was deepened, with dredging depth of over $1 \mathrm{~m}$.

\section{0s-2010s}

Between the 2000s and 2010s, with the continuous improvement of the infrastructure of Longkou Port and the implementation of large-scale artificial island projects, the land and underwater morphology of Longkou Bay study area changed drastically. Land area increased from $23.10 \mathrm{~km}^{2}$ to $29.35 \mathrm{~km}^{2}$, while the proportion of subaqueous area decreased from $78.20 \%$ of the study area to $72.34 \%$ during this period (Table 2 ). The average water depth in the study area increased from $8.16 \mathrm{~m}$ to $8.89 \mathrm{~m}$, and the water volume net gain was $6.51 \times 10^{6}$ $\mathrm{m}^{3}$ (Table 3). Erosion of more than $0.5 \mathrm{~m}$ occupied $26.79 \mathrm{~km}^{2}$, that is to say, $34.83 \%$ of the subaqueous area (Table 3), which was larger than that of any other previous period. Figure $3 \mathrm{e}$ shows that most of the west and middle shoals disappeared. Compared with the 2000s, Longkou Port was expanded westward in $2010 \mathrm{~s}$. The west side of the port was dredged with a wide range, connecting it with the channel, and the water depth changed far more than $3 \mathrm{~m}$ (Figure 4d), with local depth reaching over $20 \mathrm{~m}$ (Figure 3e). Deposition less than $1 \mathrm{~m}$ took place in the east area of Longkou Port during this period. The change of the deep trough area was basically consistent with that of the period of the 1990s-2000s. The channel was further deepened overall, with some deposition in local areas (Figure 4d). The most significant feature at this stage was that mud and sand excavation was conducted on a large scale between the channel and artificial islands. The depth changes were mostly near $3 \mathrm{~m}$. Near the northern part of the artificial islands, a great deal of sediment was dredged out by a cutter suction dredger for filling the artificial islands, leaving a large number of deep pits, which will be described in detail below.

\section{Geomorphologic Characteristics}

The high-resolution bathymetric results near the artificial island are presented in Figure $5 \mathrm{a}$, which clearly shows the seabed topographic characteristics because of dredging and filling engineering. The location, shape, and size of the deep pits can be easily identified from the multibeam bathymetry. The bathymetry of the survey area exhibits a depth ranged from 10.2 to $18.5 \mathrm{~m}$, and $43 \%$ of this area is under $16 \mathrm{~m}$. Before construction of the artificial islands, the area was relatively flat and gradually deepened seaward (from east to west). The cutter suction dredgers with long pipes (Figure 5g), playing an important role in dredging and reclamation projects, were used to blow sand and water from the seafloor into the target circle enclosed by embankment dams (Figure 5e). The seabed was dredged at a great many sites, leaving a lot of borrow pits like seafloor "scars," with the longest up to $1200 \mathrm{~m}$, drastically changing the underwater topography. Figure 5a shows that the borrow pits were mostly rectangular, and a majority of pits are connected together because of the dense mud pumping sites. These excavated pits vary in depth, with some 1-2 m, and some up to 7-8 $\mathrm{m}$ deep. The three-dimensional map of an irregularly shaped pit located in the southwest part of the survey area is shown in Figure 5b; it is about $530 \mathrm{~m}$ in length and between 130 and $220 \mathrm{~m}$ in width. The three-dimensional rendering reveals an intuitive-looking depiction of the borrow pit. A bathymetric profile across the deep pit is shown in Figure 5c, exhibiting obvious relief change and indicating that the pit has a depth of about $4 \mathrm{~m}$. It is estimated that about $3.9 \times 10^{5} \mathrm{~m}^{3}$ of material was extracted from this dredge pit. As the hydraulic reclamation work was completed less than a year ago, significant sediment erosion and siltation were not found in the survey area.

\section{DISCUSSION}

Longkou Bay has experienced rapid morphological changes during the last 50 years. The available evidence suggests that, from the 1960s to 1990s, Longkou Bay existed in a condition of dynamic equilibrium. During these three decades, net changes appear to have been fairly limited, and no significant evidence of large-scale human activities could be found. This situation evidently began to change significantly in the $2000 \mathrm{~s}$, and particularly in the 2010s. The large-scale human activities, as revealed in the previous section, greatly changed the land and underwater morphology of Longkou Bay.

Although the admiralty charts are suitable for studying patterns of morphological change (Van der Wal and Pye, 2003), their accuracy is insufficient to reveal detailed topographic changes. Advances in multibeam echosounders have enhanced researchers' ability to characterize physical aspects of the benthic environment at fine scales (Brown and Blondel, 2009; Li et al., 2017; Pickrill and Todd, 2003). In order to better understand the topography changes caused by the dredging and filling engineering, a multibeam survey should be carried out at regular intervals during the construction process of artificial islands, once a year for example.

Several factors could have contributed to the observed morphological changes in Longkou Bay. These include changes in natural environmental forcing factors, such as sea level, tidal regime, wave climate, and sediment supply (Blott et al., 2006), or human activities such as channel dredging, artificial island construction, and port development. An expert geomorphological assessment of past changes in the bay requires identifying and quantifying these environmental constraints, natural forcing factors, and human activities. However, it depends on the scope and quality of available data (Blott et al., 2006). A full discussion of each factors and their interactions relevant to the geomorphology of Longkou Bay is beyond the scope of the study, but the dominant aspects are discussed below.

The report on China's sea level compiled by the State Oceanic Administration (SOA) in 2012 suggests that the sea level along China's coastlines has risen by $2.9 \mathrm{~mm}$ per year over the past three decades (Zhang et al., 2015). Under natural conditions, the rising sea level can flood more land and erode the coast, causing retreat. Contrary to this, most coastlines of the Longkou Bay displayed a seaward-extending tendency. Land area increased from $15.92 \mathrm{~km}^{2}, 15.78 \%$ of the study area, in the $1980 \mathrm{~s}$ to $29.35 \mathrm{~km}^{2}, 27.65 \%$ of the study area, in the $2010 \mathrm{~s}$ (Table 2). The conclusion can be drawn that human influence overwhelms the natural coastal response to sea-level rise.

In general, sediment supply plays an important role in changing estuarine geomorphology (Van der Wal, Pye, and Neal, 2002; Wu et al., 2016). There is no long-standing river in this area, and only several small rivers flow into Longkou Bay. 

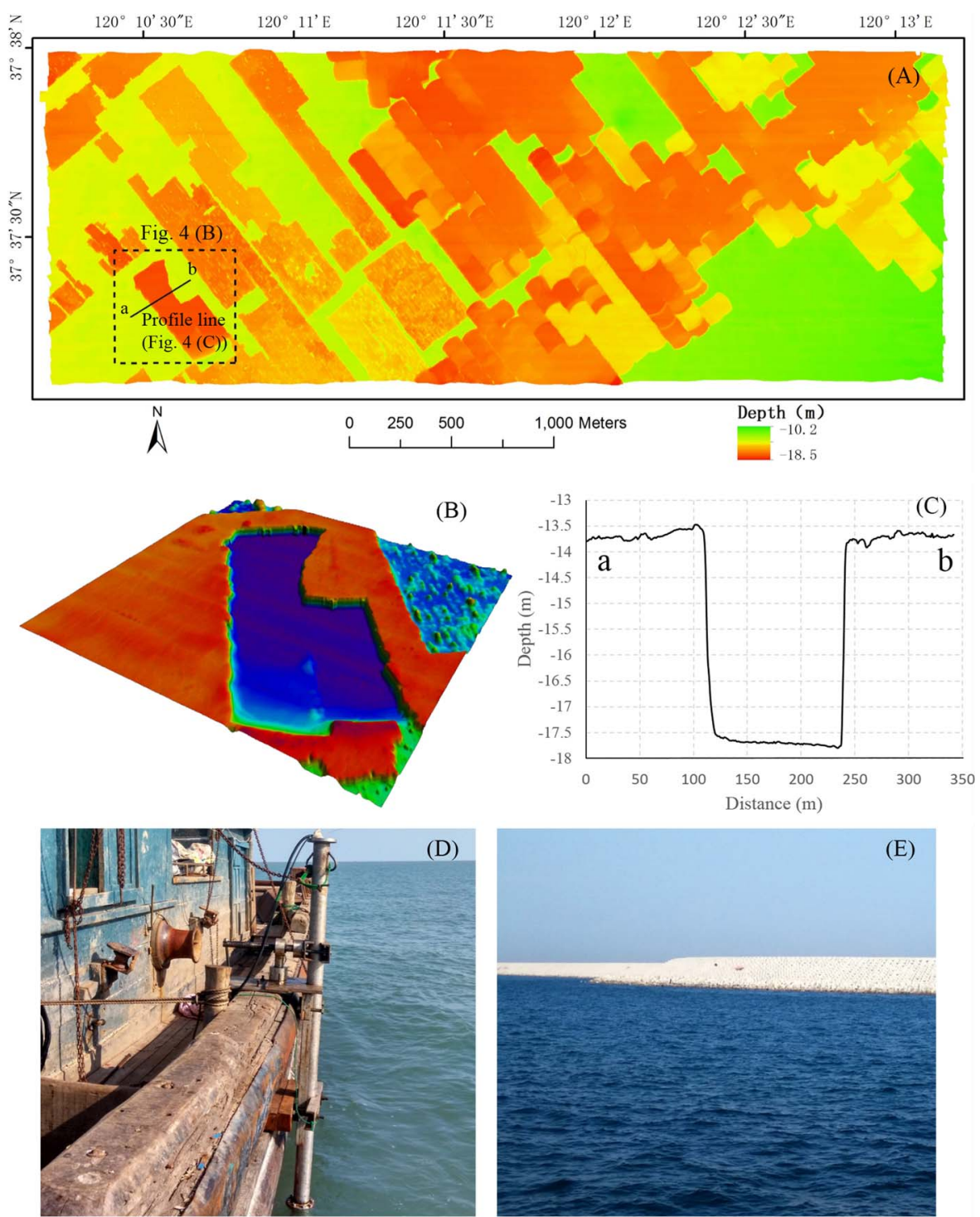

E)
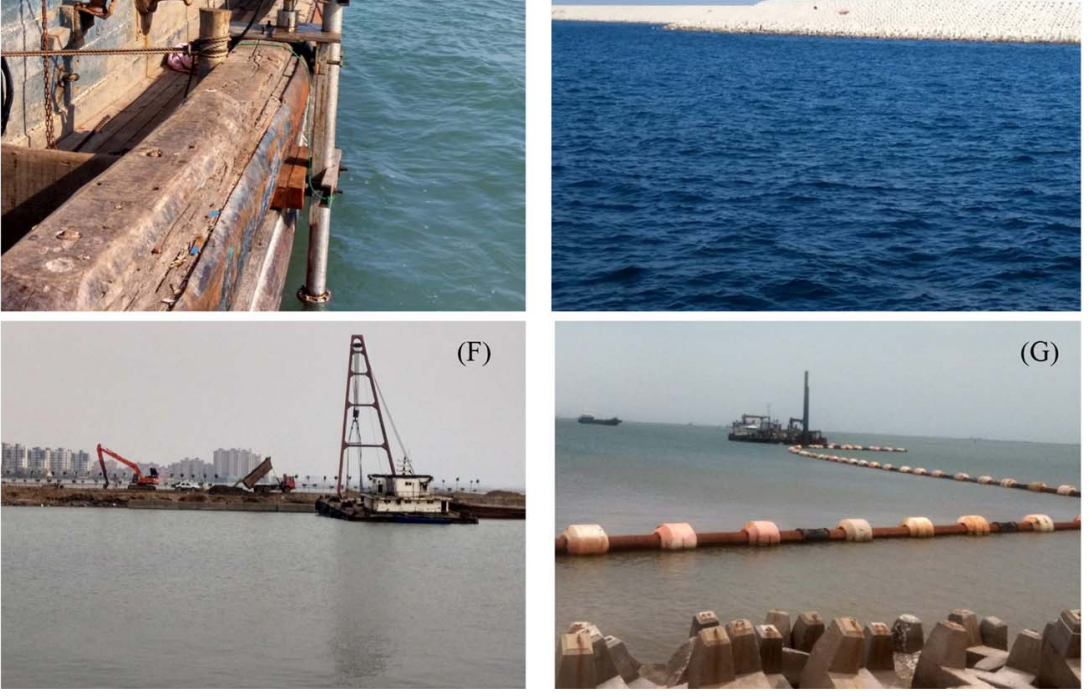

Figure 5. (a) Detailed bathymetry based on multibeam data with the location of the three-dimensional view and the profile shown in Figure $4 \mathrm{~b}$,c. (b) Threedimensional map of a typical deep pit as a result of sand pumping. (c) Bathymetric profile across the deep pit. (d) Multibeam survey vessel with the transducer mounted on the port side. (e) The dam for bank protection at the edge of the artificial islands. (f) New dock in construction near the Longkou Port. (g) A cutter suction dredger near the artificial island.

In the absence of reservoirs, the amount of river sediment transport was merely $35.7 \times 10^{4}$ to $58.3 \times 10^{4}$ t/yr $(\mathrm{Qu}$, Wang, and Feng, 1995). The sediment supply was greatly reduced due to the rapid increase of dam constructions and the integrated management of small watersheds. The natural deposition rate of this area was very small, only about $0.1 \mathrm{~cm} / \mathrm{yr}(\mathrm{Qu}, \mathrm{Wang}$, and Feng, 1995). This study showed that the water depth did not change significantly before the 2000s (the average water 
depth in the $1960 \mathrm{~s}, 1980 \mathrm{~s}$, and 1990s was 7.19, 7.43, and 7.56 $\mathrm{m}$, respectively) without large-scope human activities in Longkou Bay (Table 2). Table 3 also confirms that the percentage of no significant depth change area was $75.93 \%$ during the period of 1960 s to 1980 s and $80.18 \%$ from the 1980 s to 1990 s.

The navigation channel of Longkou Bay was maintained by dredging, particularly after the 1990s. Dredging was especially required in two areas: the vicinity of Longkou Port and the waterway (about $9600 \mathrm{~m}$ ) leading to Longkou Port (Figure $3 \mathrm{~d}, \mathrm{e})$. The dredge spoil was disposed on the seafloor near the channel in the southwest, resulting in a large area of slight deposition, which is shown in Figure 4c. The broadening and deepening of the navigation channel could be explained by the extension of Longkou Port, with the construction of a few 100,000 ton berths.

Land reclamation is one of the important human activities that can affect the morphology of bays (Dai, Liu, and Wen, 2015; Jaffe, Smith, and Foxgrover, 2007; Lane, 2004). It not only changes the length of the coastline and the shape of land in a direct way (Zhang et al., 2015), but it also changes the seabed topography tremendously. From an analysis of Table 2, 13.57 $\mathrm{km}^{2}$ of land was reclaimed during $1960 \mathrm{~s}-2010 \mathrm{~s}$ in the study area. Significant coastal area was reclaimed from the 1960 s to 2010s, causing an obvious decrease of subaqueous area in Longkou Bay (Figure 3). For example, three underwater sand spits developed in Longkou Bay, i.e. Jianzitou Spit, Guandao Spit, and Yatan Spit, which corresponded to the west shoal, middle shoal, and south shoal, respectively. Early in the 1980s, a small amount of authigenic pyrite, indicating weak sedimentation and dynamic conditions, was found in Longkou Bay by the First Institute of Oceanography, SOA, and it showed the demise of Longkou inner bay would be fast if not protected $(\mathrm{Qu}$, Wang, and Feng, 1995). However, the Yatan Spit gradually disappeared before the 2000s because of the coastal land reclamation, while most of the Jianzitou Spit and Guandao Spit have been occupied by the expansion of the Qimu Dock and recent coastal engineering projects.

Analysis of all available evidence strongly suggests that rapid and extensive morphological changes took place in Longkou Bay as a result of artificial island construction (Figures $3 \mathrm{e}, 4 \mathrm{~d}$, and $5 \mathrm{a}$ ). In the construction of artificial islands, the use of a cutter suction dredger is currently the most common method for extracting sediment from the seafloor. While the dredger is moored in deeper waters, dredged materials are pumped into a floating pipeline. These tools can help to reduce the release of fine sediment into the marine environment by discharging dredged materials close to the seabed (Zainal et al., 2012). However, it leaves dredge scars and pits (Figure 5a,b), which act as traps for sediment moved by the longshore current, further denuding adjacent beaches (Smith and Collen, 2006). Chew (1999) showed beach and nearshore sand and gravel extraction increases surface erosion by allowing waves to reach further inshore, often resulting in rapid shoreline retreat.

It is important to understand whether a given bay is infilling, eroding, or exists in morphodynamic equilibrium (Canestrelli, Lanzoni, and Fagherazzi, 2014). Natural coasts are basically in a stable or equilibrium state after a long history. Intensive anthropogenic activities will affect the balance, resulting in erosion or siltation. Human activities such as port dredging and artificial island building can alter the environment, both directly and indirectly (Barnes and $\mathrm{Hu}, 2016$ ). Although the artificial islands will provide more stable navigation conditions and a better berthing situation for Longkou Port, at the same time, there will be a certain degree of siltation due to the weakening hydrodynamic conditions. Previous research showed that the channel between the land and artificial islands was in a strong depositional state in Longkou Bay (An et al., 2013). Through numerical simulation, Zhou et al. (2014) found the velocity of the current in Longkou Bay decreased by $4-8 \mathrm{~cm} /$ $\mathrm{s}$ with the influence of the artificial island construction, causing deposition of about $4 \mathrm{~mm}$ per month, which will lead to an increase of dredging requirements. This concurs with the finding of Wang, $\mathrm{Li}$, and $\mathrm{Li}$ (2013), who showed that the sea areain the north of Tangshan Bay, China, was deposition area because of the artificial island construction.

The bay ecosystem is an important spawning ground and habitat for many marine organisms, and it is of great significance for the supplement of marine ecosystem fishery resources. Due to overfishing and intensive coastal development, the Laizhou Bay ecosystem is under unprecedented pressure, and its sustainability capacity is gradually weakening. Previous studies have shown that the individual fishery resources of Longkou Bay are significantly diminished. For example, the yellow croaker, as the dominant species in Laizhou Bay, tends to be simple in length composition and age structure, and it has obvious characteristics of younger age and smaller size in recent decades (Zhang, Wu, and Jin, 2015). Moreover, the dominant macrozoobenthos in Laizhou Bay have changed in the past few decades. Shrimps and crabs with larger size and longer life span were substituted by those being tolerant to environment changes with smaller size and shorter life span, such as some smaller bivalves, which shows that the benthic habitat of the bay has been disturbed to some degree (Cai et al., 2013). This trend is likely to be related to changes in the sediment conditions of the bay, and anthropogenic disturbances such as land reclamations projects and excess input of pollutants (Jin et al., 2013).

The terrain change caused by such a massive reclamation project will lead to the destruction of the original benthic habitat. Despite the extensive program of dredging, published data on the recovery of the marine community following dredging are limited (Jones et al., 1998). There is a danger that the submarine ecosystem reach a point of collapse, where it could no longer support the current levels of activities. Naser (2011) used a microcosm experimental approach to investigate the survival of marine organisms following the impact of infilling, and a compensatory solution for the infill and reclamation impacts was provided by Jones et al. (2007). Recovery may be possible but influenced by site-specific features. Today, huge dredging and reclamation projects are being conducted in full swing in Longkou Bay (Figure 5f). Fortunately, the Chinese government has promulgated the most stringent measures for reclamation control to ensure the sustainable development of the coastal area. Different mitigation measures will be undertaken to minimize the benthic habitat damages and create the required balance. 


\section{CONCLUSIONS}

Using admiralty charts and multibeam swath mapping in a GIS environment, this study estimated the morphological changes and showed the geomorphologic features of Longkou Bay. The method has proven efficient to explore the relationship between accretion-erosion characteristics and coastal development. Results based on 50 years of historical bathymetric data indicated that the morphological changes in the study area can be divided into three stages. (1) From the 1960s to 1990 s, topographic changes showed a patchy distribution of deposition and erosion, with natural evolution of the subaqueous topography, and there were few signs of large-scale human activities. (2) During the 1990 s to 2000 s, with the enlargements of Longkou Port, dredging of the channel, and the reclamation of coastal land, the land area increased by $27.3 \%$, and mean water depth rose from 7.56 to $8.16 \mathrm{~m}$. (3) Rapid morphological changes took place from the 2000 s to 2010 s due to the continuous construction of Longkou Port and the implementation of large-scale artificial island project with an increase of land area from 23.10 to $29.35 \mathrm{~km}^{2}$ and a water volume net gain of $6.51 \times 10^{6} \mathrm{~m}^{3}$. Intensive coastal developments such as port expansion, channel dredging, and artificial island construction were the main processes affecting the observed morphological changes in Longkou Bay. The detailed multibeam swath bathymetric map demonstrated the geomorphologic characteristics of the seafloor, with quantities of borrow pits due to dredging and filling engineering. Timely and effective measures need to be taken to reduce the impact caused by drastic morphology changes on the environment.

\section{ACKNOWLEDGMENTS}

This work was financially supported by grants from the Strategic Priority Research Program of the Chinese Academy of Sciences (No. XDA19060205), the National Key Basic Research Program of China (973) (No. 2015CB453301), and the Key Laboratory of Coastal Environmental Processes and Ecological Remediation, YICCAS (No. 2018KFJJ05).

\section{LITERATURE GITED}

An, Y.N.; Wu, J.Z.; Zhu, L.H.; Hu, R.J., and Yue, N.N., 2010. Response of erosion-deposition pattern to artifical islands construction in Longkou Bay. Marine Geology Letters, 26(10), 24-30 (in Chinese with English abstract).

An, Y.N.; Yang, K.; Wang, Y., and Li, J., 2013. Effect on trend of coastal geomorphological evolution after construction of artificial islands in Longkou Bay. Advanced Materials Research, Trans Tech Publications, 726, 3308-3312.

Barnes, B.B. and Hu, C., 2016. Island building in the South China Sea: Detection of turbidity plumes and artificial islands using Landsat and MODIS data. Scientific Reports, 6, 33194.

Blott, S.J.; Pye, K.; Van der Wal, D., and Neal, A., 2006. Long-term morphological change and its causes in the Mersey Estuary, NW England. Geomorphology, 81(1-2), 185-206.

Brown, C.J. and Blondel, P., 2009. Developments in the application of multibeam sonar backscatter for seafloor habitat mapping. Applied Acoustics, 70(10), 1242-1247.

Burrough, P.A., 1987. Principles of geographical information systems for land resources assessment. Geofisica Internacional, 144(3), $357-358$.

Cai, W.Q.; Meng, W.; Liu, L.S.; Zhu, Y.Z., and Zhou, J., 2013. Longterm trends of the dominant macrozoobenthos in Bohai Bay. Acta Scientiae Circumstantiae, 33(8), 2332-2340 (in Chinese with English abstract).
Canestrelli, A.; Lanzoni, S., and Fagherazzi, S., 2014. One-dimensional numerical modeling of the long-term morphodynamic evolution of a tidally-dominated estuary: The Lower Fly River (Papua New Guinea). Sedimentary Geology, 301, 107-119.

Chew, R.T., III, 1999. Environmental problems on the low atolls of the Marshall Islands. Journal of Geoscience Education, 47(2), 143-149.

Dai, Z.J.; Liu, J.T., and Wen, W., 2015. Morphological evolution of the South Passage in the Changjiang (Yangtze River) Estuary, China. Quaternary International, 380, 314-326.

Fenster, M.S. and FitzGerald, D.M., 1996. Morphodynamics, stratigraphy, and sediment transport patterns of the Kennebec River estuary, Maine, USA. Sedimentary Geology, 107(1-2), 99-120.

Harris, P.T. and Collins, M.B., 1984. Bedform distributions and sediment transport paths in the Bristol Channel and Severn Estuary, UK. Marine Geology, 62(1), 153-166.

Hou, X.Y.; Wu, T.; Hou, W.; Chen, Q.; Wang, Y.D., and Yu, L.J., 2016. Characteristics of coastline changes in mainland China since the early 1940s. Science China Earth Sciences, 59(9), 1791-1802.

Jabaloy-Sánchez, A.; Lobo, F.J.; Azor, A.; Bárcenas, P.; FernándezSalas, L.M.; del Río, V.D., and Pérez-Peña, J.V., 2010. Humandriven coastline changes in the Adra River deltaic system, southeast Spain. Geomorphology, 119(1), 9-22.

Jaffe, B.E.; Smith, R.E., and Foxgrover, A.C., 2007. Anthropogenic influence on sedimentation and intertidal mudflat change in San Pablo Bay, California: 1856-1983. Estuarine, Coastal and Shelf Science, 73(1-2), 175-187.

Jones, D.A.; Ealey, T.; Baca, B.; Livesey, S., and Al-Jamali, F., 2007. Gulf desert developments encompassing a marine environment, a compensatory solution to the loss of coastal habitats by infill and reclamation: The case of the Pearl City Al-Khiran, Kuwait. Aquatic Ecosystem Health \& Management, 10(3), 268-276.

Jones, D.A.; Plaza, J.; Watt, I., and Al Sanei, M., 1998. Long-term (1991-1995) monitoring of the intertidal biota of Saudi Arabia after the 1991 gulf war oil spill. Marine Pollution Bulletin, 36(6), 472 489.

Jin, X.S.; Shan, X.J.; Li, X.S.; Wang, J.; Cui, Y., and Zuo, T., 2013. Long-term changes in the fishery ecosystem structure of Laizhou Bay, China. Science China Earth Sciences, 56(3), 366-374.

Kan, H.; Urata, K.; Nagao, M.; Hori, N.; Fujita, K.; Yokoyama, Y.; Nakashima, Y.; Ohashi, T.; Goto, K., and Suzuki, A., 2015. Submerged karst landforms observed by multibeam bathymetric survey in Nagura Bay, Ishigaki Island, southwestern Japan. Geomorphology, 229, 112-124.

Lane, A., 2004. Bathymetric evolution of the Mersey Estuary, UK, 1906-1997: Causes and effects. Estuarine, Coastal and Shelf Science, 59(2), 249-263.

Li, D.; Tang, C.; Xia, C.L., and Zhang, H., 2017. Acoustic mapping and classification of benthic habitat using unsupervised learning in artificial reef water. Estuarine, Coastal and Shelf Science, 185, 1121.

Naser, H.A., 2011. Effects of reclamation on macrobenthic assemblages in the coastline of the Arabian Gulf: A microcosm experimental approach. Marine Pollution Bulletin, 62(3), 520-524.

Pickrill, R.A. and Todd, B.J., 2003. The multiple roles of acoustic mapping in integrated ocean management, Canadian Atlantic continental margin. Ocean \& Coastal Management, 46(6-7), 601614.

Qu, M.X.; Wang, W.H., and Feng, J.Z., 1995. Natural Environment of Longkou Bay. Beijing: China Ocean Press (in Chinese).

Radhi, H.; Sharples, S., and Assem, E., 2015. Impact of urban heat islands on the thermal comfort and cooling energy demand of artificial islands-A case study of AMWAJ Islands in Bahrain. Sustainable Cities and Society, 19, 310-318.

Restrepo, J.C.; Schrottke, K.; Traini, C.; Ortíz, J.C.; Orejarena, A.; Otero, L.; Higgins, A., and Marriaga, L., 2016. Sediment transport and geomorphological change in a high-discharge tropical delta (Magdalena River, Colombia): Insights from a period of intense change and human intervention (1990-2010). Journal of Coastal Research, 32(3), 575-589.

Smith, R. and Collen, J.D., 2006. Three-dimensional imaging of lagoon aggregate extraction and resources: Case study from Majuro 
Atoll, Marshall Islands. Environmental \& Engineering Geoscience, 12(2), 93-102.

Townend, I., 2005. An examination of empirical stability relationships for UK estuaries. Journal of Coastal Research, 21(5), 1042-1053.

Van der Wal, D. and Pye, K., 2003. The use of historical bathymetric charts in a GIS to assess morphological change in estuaries. Geographical Journal, 169(1), 21-31.

Van der Wal, D.; Pye, K., and Neal, A., 2002. Long-term morphological change in the Ribble Estuary, northwest England. Marine Geology, 189(3-4), 249-266.

Wang, Q.; Zhong, S.Y.; Li, X.Y.; Zhan, C.; Wang, X., and Liu, P., 2016. Supratidal land use change and its morphodynamic effects along the eastern coast of Laizhou Bay during the recent 50 years. In: Harff, J. and Zhang, H. (eds.), Environmental Processes and the Natural and Anthropogenic Forcing in the Bohai Sea, Eastern Asia. Journal of Coastal Research, Special Issue No. 74, pp. 83-94.

Wang, Y.H.; Dong, P.; Oguchi, T.; Chen, S.L., and Shen, H.T., 2013. Long-term (1842-2006) morphological change and equilibrium state of the Changjiang (Yangtze) Estuary, China. Continental Shelf Research, 56, 71-81.

Wang, Y.; Li, X., and Li, M.C., 2013. Research of the artificial island construction impact on marine deposit dynamic environment. Applied Mechanics and Materials, Trans Tech Publications, 405, 1431-1436.
Wolanski, E., 2006. The evolution time scale of macro-tidal estuaries: Examples from the Pacific Rim. Estuarine Coastal and Shelf Science, 66(3-4), 544-549.

Wu, T.; Hou, X.Y., and Xu, X.L., 2014. Spatio-temporal characteristics of the mainland coastline utilization degree over the last 70 years in China. Ocean \& Coastal Management, 98, 150-157.

Wu, Z.Y.; Saito, Y.; Zhao, D.N.; Zhou, J.Q.; Cao, Z.Y.; Li, S.J.; Shang, J.H., and Liang, Y.Y., 2016. Impact of human activities on subaqueous topographic change in Lingding Bay of the Pearl River Estuary, China, during 1955-2013. Scientific Reports, 6, 37742.

Zainal, K.; Al-Madany, I.; Al-Sayed, H.; Khamis, A.; Al Shuhaby, S.; Al Hisaby, A.; Elhoussiny, W., and Khalaf, E., 2012. The cumulative impacts of reclamation and dredging on the marine ecology and land-use in the Kingdom of Bahrain. Marine Pollution Bulletin, 64(7), 1452-1458.

Zhang, B.; Wu, Q., and Jin, X.S., 2015. Interannual variation in the food web of commercially harvested species in Laizhou Bay from 1959 to 2011. Journal of Fishery Sciences of China, 22(2), 278-287 (in Chinese with English abstract).

Zhang, W.; Xu, Y.; Hoitink, A.J.F.; Sassi, M.G.; Zheng, J.H.; Chen, X.W., and Zhang, C., 2015. Morphological change in the Pearl River Delta, China. Marine Geology, 363, 202-219.

Zhou, G.Z.; Feng, X.L.; Liu, J.; Liu, X., and Xu, F., 2014. Prediction of erosion evolution and deposition in the east coast of the Laizhou Bay after the implemention of the coastal planning. Marine Sciences, 38(1), 15-19 (in Chinese with English abstract). 